\title{
CONTRIBUIÇÃO AO CONHECIMENTO DE ASSOCIAÇÕES MÁFICO-ULTRAMÁFICAS PRECAMBRIANAS: DESENVOLVIMENTO E ESTÁGIO ATUAL DO ESTUDO
}

\author{
V.A.V.Girardi ${ }^{1}$
}

Há mais de uma década tem-se, em colaboração com vários colegas, desenvolvido estudos em rochas máfico-ultramáficas. O presente trabalho tem por objetivo relatar sucintamente a evolução dos estudos efetuados nas associações precambrianas. Discriminar-se-ão em seguida os diversos tipos estudados.

1. As Suítes Komatíticas - foram analisadas pormenorizadamente as seqüências komatíticas dos cinturōes verdes de Hidrolina e Crixás. Neste, ARNDT et al. (1989) determinaram idade em torno de $2.7 \mathrm{Ga}$. Ambos os cinturóes ocorrem em terrenos muito deformados. Suas seqüências estratigráficas incluem uma porção komatítica inferior (komatítos e basaltos komatíticos intercalados com metasedimentos químicos) seguidas por mármores, metatoleítos, metadacitos e metariolitos. Metapelitos e sedimentos arenosos ocorrem no topo. Apesar do severo metamorfismo, a seqüência máfico-ultramáfica de Hidrolina mostra "trend" ígneo bem preservado. Inferiu-se que os líquidos komatíticos primários tem $\mathrm{MgO}$ variando entre $9 \mathrm{e}$ $15 \%$, talvez alcançando $24 \%$. Todos os peridotitos komatíticos parecem ser mistura de líquidos primários e material mantélico. Modelos de fusão parcial baseados em elementos maiores e traços e comparação com razões de elementos traços em condritos sugerem que os líquidos primários relacionam-se à fusão de manto formado por espinélio peridotito e que a fonte das unidades superiores da seqüências máfico-ultramáficas era empobrecida em elementos incompatíveis em relação às inferiores, fato que sugere heterogeneidade matélica (RIVALENTI et al., 1989). Em Crixás, embora as feições primárias estejam melhor conservadas, o processo ígneo é menos claro. O comportamento anômalo de $\mathrm{Ca}$ e $\mathrm{Al}$ é

${ }^{\mathrm{1}}$ Departamento de Mineralogia e Petrologia, Instituto de Geociências/USP, São Paulo. 
tentativamente atribuído a processo de cristalização cujos controles não são evidentes. Ocorrem diferenças no comportamento de elementos traços atribuídos à heterogeneidade composicional e modal da fonte mantélica, provavelmente mais rica em espinélio do que a de Hidrolina (RIVALENTI et al., no prelo).

2. Os Grandes Complexos Máfico-Ultramáficos - três grandes complexos máfico-ultramáficos ocorrem no centro de Goiás: Cana Brava, Niquelândia e Barro Alto. Eles constituem um alinhamento NNE com cerca de $300 \mathrm{~km}$. Vários modelos genéticos foram aventados, a saber: corpos alpinos, suítes ofiolitícas, maciços estratiformes, maciços em parte estratiformes, em parte alpinos. Trabalhos de campo, estudos de petrofábrica, petrológicos e geoquímicos (GIRARDI et al., 1981; GIRARDI \& KURAT 1982, GIRARDI et al., 1986; SIGHINOLFI et al., 1983; MAZZUCHELLI et al., 1983; DREHER et al., 1989) mostraram evidências de que Barro Alto (parte nordeste), Cana Brava e Niquelândia podem ser interpretados como corpos intracratônicos estratiformes derivados por cristalização fracionada de magmas basálticos a pressões baixas e moderadas. Tais conclusões foram recentemente reforçadas a partir de estudos gravimétricos (FEININGER et al., no prelo) que mostram que o complexo de Niquelândia constitui uma fatia cuja extensão em profundidade não excede $6 \mathrm{~km}$. $\mathrm{O}$ mesmo padrão foi obtido em Barro Alto, indicando que os grandes complexos são separados e foram intrudidos em região de sutura continental. Episódios de reequilíbrio e metamorfismo (CANDIA et al., 1989) atingiram tais corpos, cuja formação parece se reportar ao Proterozóico Inferior (FUGI, 1989).

3. Os Complexos de Pequeno e Médio Porte - complexos estratiformes de pequeno e médio porte foram estudados a SW de Goiás e no Estado do Paraná. Os complexos de Mangabal I e Mangabal II, em Sanclerlândia, Goiás, contém mineralizações de sulfeto de $\mathrm{Ni}$, Co e Cu. Derivam de magma toleítico diferenciado a pressões baixas (CANDIA \& GIRARDI, 1985) e foram metamorfizados em condições de alto grau a aproximadamente $700-800^{\circ} \mathrm{C}$ e $6,5 \mathrm{~kb}$ (CANDIA \& GIRARDI, no prelo). O complexo Piên provém da diferenciação de magma olivina toleítico diferenciado a pressão moderada, tendo posteriormente sofrido a ação de 3 ciclos de metamorfismo, o primeiro a cerca de $850-950^{\circ} \mathrm{C}$ e 5-7 $\mathrm{Kb}$ (GIRARDI \& ULBRICH, 1980).

Além desses, ocorrem na região sudoeste de Goiás (Morro Feio, Cromínia, Abadânia, Pirenópolis) pequenos corpos dunito-peridotíticos parcial a totalmente serpentizados a talcificados, classificados por alguns autores como alpinos, derivados do manto. 
4. Diques máficos - Enxames de diques básicos estão sendo estudados no sudoeste do Uruguai e na região de Uauá, Bahia. Os diques do sudoeste do Uruguai tem direção N60-80E. Sua

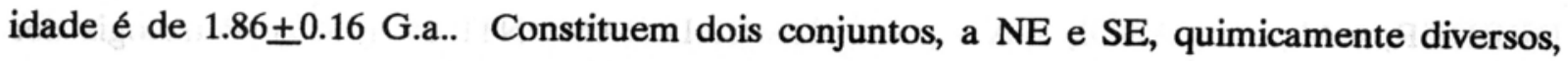
principalmente no que se refere a teor de $\mathrm{mg}, \mathrm{TiO}_{2}$ e incompatíveis. Sua derivação é compatível com fusão parcial (cerca de 10\%) de fonte mantélica tipo granada peridotito levemente enriquecida. O padrão $\mathrm{La} / \mathrm{Nb}$ é compatível com o ambiente continental (BOSSI et al., 1990).

Duas gerações de diques máficos, ambos exibindo corpos ígneos preservados e metamorfoseados em condições de fácies xisto verde a anfibolito ocorrem em Uauá, Bahia. Dados geocronológicos preliminares indicam cerca de 2.0 G.a. (LEAL \& MENEZES, 1990).

\section{REFERÊNCIAS BIBLIOGRÁFICAS}

ARNDT, N.T.; TEIXEIRA, N.A.; WHITE, W.M. (1989) Bizarre geochemistry of komatiites from the Crixás Greenstone belt, Brazil. Contributions to Mineralogy and Petrology, 101:187-197.

BOSSI, J.; CAMPAL, N.; CIVETTA, L.; DEMARCHI, G.; GIRARDI, V.A.V.; MAZZUCCHELLI, M.; PICCIRILLO, E.M.; RIVALENTI, G.; SINIGOI, S.; TEIXEIRA, W.; FRAGOSO-CESAR, A.R. (1990) Aspectos petrológicos e geocronológicos do enxame de diques básicos precambrianos do Uruguai. In: WORKSHOP DIQUES MÁFICOS DO BRASIL, 2., São Paulo, 1990. Boletim especial trabalhos apresentados. São Paulo, IUGS/UNESCO. p.6-13.

CANDIA, M.A.F. \& GIRARDI, V.A.V. (1985) Geologia e Petrologia dos complexos máficosultramáficos de Mangabal I e Mangabal II, Sanclerlândia, Goiás. Revista Brasileira de Geociências, 15(3):221-230.

CANDIA, M.A.F. \& GIRARDI, V.A.V. (no prelo) A transição gabro-anfibolito nos Complexos Mangabal I e II, Sanclerlândia, Goiás. Boletim IG-USP, Série Científica.

CANDIA, M.A.F.; MAZZUCCHELLI, M.; SIENA, F. (1989) Sub-solidus reactions and corona strutures in the Niquelândia layered complex (central Goiás), Brazil. Mineralogy 
and Petrology, 40(1):17-37.

DREHER, A.M.; GIRARDI, V.A.V.; COMIN-CHIARAMONTI, P. (1989) Petrologia dos rodingitos do complexo máfico-ultramáfico de Cana Brava, Goiás. Revista Brasileira de Geociências, 19(2):224-236.

FEININGER, T.; DANTAS, J.J.; GIRARDI, V.A.V. (no prelo) Gravity interpretation and possible regional significance of the Niquelândia layered basic-ultrabasic complex, Brazil. Journal of South American Earth Sciences.

FUGI, M.Y. (1989) REE Geochemistry and Sm/Nd geochronology of the Cana Brava Complex, Brazil. Master Thesis - Kobe University - Japan (não publicado).

GIRARDI, V.A.V. \& ULBRICH, H.H.G.J. (1980) Origin and evolution of the Piên maficultramafic complex, Southern Brazil. Journal of Geology, 88(3):251-269.

GIRARDI, V.A.V.; RIVALENTI, G.; SIENA, F.; SINIGOI, S. (1981) Precambrian Barro Alto complex of Goiás, Brazil: bulk geochemistry and phase equilibria. Neues Jahrbuch für Mineralogie. Abhandlungen, 142(3):270-291.

GIRARDI, V.A.V. \& KURAT, G. (1982) Precambrian lower crustal mafic and ultramafic rocks of the Cana Brava Complex Brazil: mineral composition and evolution. Revista Brasileira de Geociências, 12(1-3):312-323.

GIRARDI, V.A.V.; RIVALENTI, G.; SINIGOI, S. (1986) The petrogenesis of the Niquêlandia layered basic-ultrabasic complex, Central Goiás, Brazil. Journal of Petrology, 27(3):715-744.

LEAL, L.R.B. \& MENEZES, A.B. (1990) O exame de Diques Máficos de Uauá: aspectos geológicos e petrográficos. In: WORKSHOP DIQUES MÁFICOS DO BRASIL, 2., São Paulo, 1990. Boletim especial trabalhos apresentados. São Paulo, IUGS/UNESCO. p.55-58.

MAZZUCCHELLI, M.; SIENA, F.; GIRARDI, V.A.V. (1983) Textural features and olivine 
fabrics as petrogenetic indicators in the Niquelândia Complex of Central Goiás, Brazil. Neues Jahrbuch für Mineralogie. Abhandlungen, 148(1):50-57.

RIVALENTI, G.; GIRARDI, V.A.V.; COLTORTI, M.; CORREIA, C.T.; MAZZUCCHELLI, M. (1989) Geochemical models for the petrogenesis of komatiites from the Hidrolina Greenstone Belt Central Goiás, Brazil. Journal of Petrology, 30(1):195-197.

RIVALENTI, G.: MAZZUCCHELLI, M.: GIRARDI, V.A.V.: CANDIA, M.A.F.: COLTORI, M.: CORREIA, C.T.: SIENA, F.: FINATTI, G. (no prelo) Geochemical variability in the Greenstone Belts of Goiás (Brazil): the Hidrolina and Crixás sequences. Revista Brasileira de Geociências.

SIGHINOLFI, G.P.: GIRARDI, V.A.V.; RIVALENTI, G.; SINIGOI, S.; ROSSI, A. (1983) PGE, Au and Ag distribution in the precambrian Niquelândia Complex, Central Goiás, Brazil. Revista Brasileira de Geociências, 13(1):52-55. 